\title{
O MOVIMENTO ESTUDANTIL EM 1968 PELAS LENTES DO CONSELHO DE SEGURANÇA NACIONAL
}

\section{Antonio Mauricio Freitas Brito}

O protesto estudantil brasileiro no "ano mágico" de 1968 não passou despercebido pelo Conselho de Segurança Nacional (CSN). Congregando 25 membros no período - 15 militares $^{2}$ e 10 civis $^{3}$-, o Conselho se constituiu em um importante espaço para elaboração da política geral governista durante a ditadura militar. Além disso, "foi um foro central da política repressiva da ditadura, atuando decisivamente na cassação de mandatos e da suspeição de direitos políticos de opositores do regime $e$ de suspeitos de corrupção" 4 .

Tendo como função "assessorar o Presidente da república na formulação e na conduta da segurança nacional", o $\mathrm{CSN}^{5}$ pautou os terremotos políticos que abalaram o Brasil em 1968, especialmente a crise estudantil - discutida na $42^{\circ}$ reunião realizada em duas seções de caráter secreto (11/07/1968 e 16/07/1968). De acordo com Guilherme de Almeida, "as palavras "estudante", "estudantil" ou assemelhadas aparecem 119 vezes nas 79 páginas da ata dessa reunião, citadas por ministros militares e civis, o que demonstra como a "subversão" do setor estudantil impunha-se na pauta de preocupações do governo naquele momento"6.

Pouco exploradas pela historiografia, lidas nas linhas e entrelinhas, as atas dessas reuniões interministeriais são fontes relevantes para uma história política da ditadura militar que capte os jogos de poder entre os "de cima". A própria realização das reuniões deve ser vista como um acontecimento naquela conjuntura. Acrescente-se que são raros os trabalhos que investiguem as interpretações do governo sobre o protesto estudantil e as suas principais chaves de leitura. Visando contribuir com esta abordagem, estivemos atentos ao jargão, gramática, ideário, medos, ansiedades, argumentos, sistemas de acusação, imagens de si e do outro, disputas, estratégias e modelos de análise presentes nas diferentes falas dos participantes.

A percepção do movimento estudantil (ME) pelas lentes do CSN ajuda a compreender aspectos da conjuntura de 1968 e das representações anticomunistas ${ }^{7}$ elaboradas sobre a juventude crítica ao

\footnotetext{
${ }^{1}$ Professor do Departamento de História e do Programa de Pós-Graduação em História Social UFBA. Realiza estágio Pós Doutoral no PPGH- UFMG. E-mail: mafbrito@hotmail.com

${ }^{2}$ Marechal Costa e Silva (Presidente da República), General de Brigada Jayme Portella de Mello (Chefe do Gabinete da Presidência da República e Secretário Geral do Conselho de Segurança Nacional), Almirante de Esquadra Augusto Hamann Rademaker Grunewald (Ministro da Marinha), General de Exército Aurélio de Lyra Tavares (Ministro do Exército), Coronel Mario Andreazza (Ministro dos Transportes), Senador Jarbas Passarinho (Ministro do Trabalho e Previdência Social), Marechal do Ar Marcio de Souza e Mello (Ministro da Aeronáutica), General de Divisão Edmundo de Macedo Soares e Silva (Ministro da Indústria e Comércio), Deputado Coronel da Reserva José Costa Cavalcanti (Ministro das Minas e Energia), General de Divisão Afonso Augusto de Albuquerque Lima (Ministro do Interior), General de Divisão Emilio Garrastazu Médici (Chefe do Serviço Nacional de Informações), General de Exército Orlando Geisel (Chefe do Estado Maior das Forças Armadas), Almirante de Esquadra José Moreira Maia (Chefe do Estado Maior da Armada), General do Exército Adalberto Pereira dos Santos (Chefe do Estado Maior do Exército) e Tenente-Brigadeiro Carlos Alberto Huet de Oliveira Sampaio (Chefe do Estado Maior da Aeronáutica). ATA CSN, 11/07/1968.

${ }^{3}$ Doutor Pedro Aleixo (Vice-Presidente), Deputado Rondon Pacheco (Chefe do Gabinete Civil da Presidência da República), Doutor Luiz Antonio da Gama e Silva (Ministro da Justiça), Deputado José de Magalhães Pinto (Ministro das Relações Exteriores), Doutor Antonio Delfim Netto (Ministro da Fazenda), Doutor Ivo Arzua Pereira (Ministro da Agricultura), Deputado Tarso de Moraes Dutra (Ministro da Educação e Cultura), Doutor Leonel Tavares Miranda (Ministro da Saúde), Doutor Hélio Marcos Penna Beltrão (Ministro do Planejamento e Coordenação Geral), Professor Carlos Furtado de Simas (Ministro das Comunicações). ATA CSN, 11/07/1968.

${ }^{4}$ ALMEIDA, Guilherme Bacha de. O Conselho de Segurança Nacional e a ditadura (1964-1969). In: MOTTA, Rodrigo Patto Sá (org.). Ditaduras militares: Brasil, Argentina, Chile e Uruguai. Belo Horizonte: Editora UFMG, 2015, p. 84.

5 "Além da reunião interministerial, (...) a estrutura do Conselho contemplava uma Secretaria Geral, uma Comissão de Estudos, uma Comissão de Fronteiras e Seções de Segurança Nacional em todos os ministérios civis, que depois viriam a ser chamadas de Divisões de Segurança e Informação (DSI) e representavam um "escritório" do CSN em cada pasta civil". ALMEIDA, O Conselho de Segurança..., p. 85.

${ }^{6}$ ALMEIDA, O Conselho de Segurança..., p. 96.

7 "Estamos falando de representações mentais, ou seja, do processo de construção de ideias, signos ou imagens por meio do qual os homens interpretam e conferem sentido à realidade. Em essência, trata-se de perceber a visão dos anticomunistas sobre seus inimigos revolucionários: como eles pensavam, sentiam, imaginavam e viam os comunistas e o comunismo".
} 
regime no tempo da ditadura. Permite também refletir sobre a influência, abrangência, circularidade e lógica do discurso anticomunista no Brasil naquele período, haja vista que aquelas leituras se reproduziram em outras esferas e mobilizaram diferentes atores - da imprensa até membros do aparelho de repressão política.

As atas resultaram de uma reunião do CSN de natureza secreta. Sua disponibilização para a consulta pública ocorreu num contexto mais amplo de abertura de novos acervos sobre o período. Atualmente, estão armazenadas no Arquivo Nacional (Rio de Janeiro) e podem ser consultadas on-line na íntegra com as diferentes falas dos emissores transcritas - tal qual foi lida na reunião e/ou redigida pela secretaria responsável pela fabricação da ata.

Algumas das pessoas que emitiram opinião são personagens públicas cuja biografia e trajetória poderiam sofisticar a apreciação da fonte enriquecendo a compreensão do CSN como espaço de poder e saber. Este é apenas um exemplo para sublinhar o quanto a documentação trata de diferentes objetos. Não obstante esse potencial, a leitura das atas foi orientada para reter os principais diagnósticos acerca da questão estudantil. Neste quesito, quase não houve dissenso e o tom predominante da abordagem foi a "visão militar sobre o ME". Isso é uma evidência da ampliação do protagonismo militar nos rumos do governo e do regime. As diferenças de encaminhamentos emergiram com muita sutileza e, paradoxalmente, talvez sejam indícios das tensões dos bastidores.

As atas apresentam a visão veiculada individualmente por cada membro do CSN definida aqui como um pronunciamento, ou seja, o "ato ou efeito de publicamente expressar uma opinião, manifestar-se em defesa de dadas teses, posições políticas, morais, (...) Trata-se do ato de exprimir-se verbalmente; de proferir ou articular um discurso; de ler em voz alta e clara uma peça de oratória; de manifestar o que pensa ou sente; de emitir sua opinião"8. Antes de explorar os fragmentos dos pronunciamentos, convém apresentar um breve panorama sobre as relações entre Costa e Silva e o ME na conjuntura da crise.

\section{O Governo Costa e Silva e o movimento estudantil}

O Marechal Costa e Silva assumiu o governo em março de 1967 após uma campanha marcada pela ambiguidade "buscando conciliar as aparências de continuidade democrática e as expectativas da

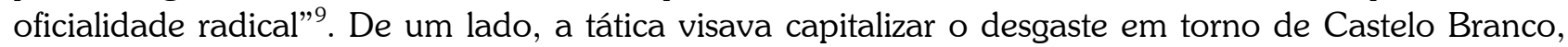
alvo de críticas em função do uso de instrumentos autoritários desde abril de 1966 para "reprimir as dissidências e amordaçar o congresso" a partir das "prerrogativas de cassação de mandatos e direitos políticos concedidas pelo AI-2". As aprovações da Lei de Imprensa, da Lei de Segurança Nacional e da nova Constituição acentuavam o verniz autoritário do regime, geraram uma oposição democrática, enquanto categorias sociais mostravam descontentamento com a política econômica geral. Por outro lado, a campanha reuniu partidários críticos do "círculo presidencial castelista [que] seria degradado" pela presença de "um amontoado de "pseudorrevolucionários" engessados por prevenções legalistas e civilistas" 10 .

Para além do discurso, "as promessas de "diálogo" (logo abandonadas (...) para serem outra vez retomadas e depois novamente deixadas de lado)" vinham acompanhadas do processo de militarização ${ }^{11}$ : "a crescente contradição entre a "profissão de fé" liberal-democrática dos detentores do

MOTTA, Rodrigo Patto Sá. Em guarda contra o perigo vermelho. O anticomunismo no Brasil. São Paulo: Editora Perspectiva/Fapesp, 2002, p. XXV.

${ }^{8}$ ALBUQUERQUE JÚNIOR, Durval Muniz. A dimensão retórica da historiografia. In: PINSKI, Carla \& LUCA, Tânia Regina de (org.). O historiador e suas fontes. São Paulo: Contexto, 2009, p. 225. Este artigo se inspira em algumas das possibilidades oferecidas pelo autor no trato dos discursos e pronunciamentos.

${ }^{9} \mathrm{CHIRIO}$, Maud. A política nos quartéis: Revoltas e protestos de oficiais na ditadura militar brasileira. Rio de Janeiro: Zahar, 2012 , p. 97.

${ }^{10}$ CHIRIO, A política nos quartéis..., p. 96.

${ }^{11}$ A equipe escolhida por Costa e Silva foi majoritariamente militar, além de incorporar personagens identificados com a "linha dura", especialmente Augusto Rademaker (Ministro da Marinha), Márcio de Souza e Mello (Ministro da Marinha), Jayme Portella de Mello (Chefe da Casa Civil e Secretário Geral do CSN), Ernesto Garrastazu Médici (Chefe do SNI), José Cavalcanti (Ministro das Minas e Energia), Afonso de Albuquerque e Lima (Ministro do Interior). O novo governo também acolheu coronéis mais jovens da "primeira linha dura" como Francisco Boaventura, Florimar Campelo, Mourão Filho. Alguns civis também se conectavam com essa perspectiva, a exemplo de Gama e Silva. Por outro lado, havia tentativa de manter equilíbrio com outros setores militares e civis não identificados com a linha dura, nem com a extrema direita. CHIRIO, $\mathrm{A}$ 
poder (...) e as práticas efetivas de progressiva militarização do Estado e "fechamento" de cena política". Segundo Martins Filho, "o movimento estudantil viveu com mais intensidade que qualquer outro setor a oscilação entre "diálogo" e repressão"12.

O mandato de Costa e Silva já encontrou um movimento estudantil relativamente reorganizado nacionalmente. Após a repressão sofrida com o golpe de 1964, o período 1965 e 1966 marcou a retomada da esquerda no movimento estudantil universitário. Além disso, aquele ME já era "predisposto contra as políticas do regime, principalmente devido à memória das violentas ações militares e policiais de setembro de 1966"13.

O governo prometeu diálogo com os estudantes, mas reprimiu as primeiras manifestações em 1967 e proibiu o $29^{\circ}$ Congresso da $\mathrm{UNE}^{14}$. O início de 1968 teve como marca a criação de uma comissão especial para elaborar a política do governo para os estudantes - dirigida pelo Coronel Meira Matos. Também em janeiro, Costa e Silva baixou nova regulamentação (Decreto-lei nº. 348, 04/01/1968) do Conselho de Segurança Nacional. A oposição criticou a ação como parte de um endurecimento do regime e "submissão do governo ao dispositivo militar" 15 .

No campo da oposição, setores do Movimento Democrático Brasileiro (MDB) e da Aliança Renovadora Nacional (ARENA) nutriam insatisfação com a centralização progressiva do poder nas mãos do executivo Federal. Além disso, Carlos Lacerda, Juscelino Kubistchek e João Goulart divulgaram um manifesto da Frente Ampla em março de 1967. Em abril de 1968, a Frente seria fechada. Estes setores civis se somarão ao $\mathrm{ME} \mathrm{-} \mathrm{cada} \mathrm{um} \mathrm{na} \mathrm{sua} \mathrm{raia} \mathrm{-} \mathrm{na} \mathrm{oposição} \mathrm{civil} \mathrm{à}$ "militarização das questões políticas", em meio a rumores de outro Ato institucional como resultado da pressão de setores "duros" 16 das Forças Armadas.

O ME começou efervescente em 1968 reivindicando a matrícula dos "excedentes" - aprovados no vestibular em classificação inferior ao número de vagas. O número já havia subido de 27.253 matrículas (1945) para 278.295 (1968), mas os universitários representavam ínfimos 0,2\% da população brasileira. Além da luta pela ampliação de vagas nas universidades, o ME criticava a política educacional do governo que, dentre outros aspectos, "reduziu ainda mais o percentual dos recursos consignados à Educação no Orçamento da União, fixando para 1968 em 7,7\% do total - quando apresentara $11 \%$ em 1965, 9,7\% em 1966 e 8,7\% em 1967"17.

O fluxo de mobilizações estudantis ganhou impulso a partir da morte do estudante Edson Luís, no Rio de Janeiro, em 28 de março, no Restaurante Calabouço ${ }^{18}$. Há uma farta bibliografia sobre o movimento estudantil brasileiro que se detém nas repercussões do acontecimento ${ }^{19}$. Para os objetivos

política nos quartéis..., p. 98-100.

${ }^{12}$ MARTINS FILHO, João Roberto. Movimento estudantil e ditadura militar (1964-1968). Campinas: Papirus, 1987, p. 134.

${ }^{13}$ MARTINS FILHO, Movimento estudantil..., p. 134.

${ }^{14}$ VALLE, Maria Ribeiro do. 1968, O diálogo é a violência: movimento estudantil e ditadura militar no Brasil. Campinas, SP: Editora da Unicamp, 1999.

${ }^{15}$ VALLE, 1968: o diálogo..., p. 40.

16 "A mais impressionante das iniciativas dos "duros", embora denunciada somente no segundo semestre, ocorrera na altura da passeata dos cem mil. Nessa ocasião, um grupo de militares vinculados ao Ministro da Aeronáutica chegou a planejar minuciosamente a ação de uma equipe de atiradores de elite que visava assassinar os principais líderes estudantis durante a manifestação. Encontrando resistências no seio do PARA-SAR, organismo militar convidado a efetuar a operação, esta acabou não se realizando". MARTINS FILHO, Movimento estudantil..., 1987, p. 142.

${ }^{17}$ POERNER, Artur. O Poder Jovem. História da participação política dos estudantes brasileiros. São Paulo: Centro de Memória da Juventude, 1995, p. 263.

${ }^{18} \mathrm{Na}$ reunião do CSN, o Ministro da Aeronáutica apresentará solução radical: "Para o Ministério da Aeronáutica, há um ponto que considero importante e que deixou de ser debatido. É o restaurante Calabouço. Julgo que deva ser tomada uma providência urgente, para sua demolição, constituindo sua simples existência uma ameaça permanente à Segurança do Edifício do Ministério da Aeronáutica, do quartel general da terceira zona aérea e dos avióes que estacionam e, muitas vezes, o próprio avião de Vossa Excelência. Julgo imprescindível a limpeza daquela área que uma vez desobstruída poderá ser transformada em um estacionamento de automóveis como era anteriormente". ATA CSN, 11/07/1968, p. 22.

${ }^{19}$ Ver, entre outros, POERNER, O Poder Jovem.... (1 $1^{\mathrm{a}}$ edição: 1968); MARTINS FILHO, João Roberto. Movimento estudantil e ditadura militar (1964-1968). Campinas: Papirus, 1987; MARTINS FILHO, João Roberto. 1968 faz 30 anos. Campinas, SP: Mercado de Letras; São Paulo: Fapesp; São Carlos, SP: Editora da Universidade de São Carlos, 1998; VALLE, Maria Ribeiro do. 1968: o diálogo é a violência - Movimento estudantil e ditadura militar no Brasil. Campinas: Editora da Unicamp, 1999; GARCIA, Marco Aurélio \& VIEIRA, Maria Alice. Rebeldes e contestadores - 1968: Brasil, França e Alemanha. São Paulo: Editora Fundação Perseu Abramo, 1999; CARDOSO, Irene. Para uma crítica do presente. São Paulo: USP, Editora 34, 2001; HEGEMEYER, Rafael Rosa. Caminhando e cantando: o imaginário do movimento estudantil brasileiro de 1968. São Paulo: EDUSP, 2016. 
do artigo, merece destaque Ribeiro do Valle que investigou a imprensa como fonte e ator privilegiado que disputou sentidos relacionados à morte do jovem. A autora afirma que a Revista Visão atribuiu aos estudantes parte da responsabilidade pelo incidente por ameaçar a tranquilidade nacional. Aliado a isso, o despreparo da Polícia da Guanabara deu ao ME "um corpo de estudante morto" e o "radicalismo estudantil" iria "exibi-lo ao máximo, com agitação forte, para atrair a classe estudantil à luta política" 20 .

Mostrando a imprensa como campo heterogêneo, a autora apresenta outro jornal com perspectiva radicalmente diferente de análise do desfecho trágico:

A Polícia Militar da Guanabara transformou, ontem à noite, as imediações do novo restaurante do Calabouço em verdadeira praça de guerra, matando um estudante, ferindo outro e mais um servidor do INPS, após vários choques da corporação invadirem o local, onde grupos de estudantes discutiam a realização (...) de uma passeata de protesto contra as condições de higiene do restaurante. Depois de espancar moças e rapazes, os policiais os puseram em fuga, fazendo vários disparos, um dos quais atingiu mortalmente Edson Luís de Lima Souto (...) A ação policial no Calabouço foi desencadeada de surpresa e ocorreu quando numerosos estudantes faziam refeições. As paredes do restaurante ficaram crivadas de balas de grosso calibre. $^{21}$

Coberturas jornalísticas diferentes à parte, o assassinato do estudante foi o "batismo de sangue do movimento estudantil" ${ }^{22}$ que ensejou a dialética repressão-resistência traduzida em "26 grandes passeatas em 15 capitais". Em junho houve "16 passeatas em 07 capitais", incluindo a passeata dos cem mil no Rio de Janeiro ${ }^{23}$. Protagonizadas pelos estudantes, as mobilizações contra a violência policial contaram com o apoio de padres, intelectuais, artistas, mães e pais de alunos e outros setores das camadas médias urbanas. Conflitos com a Polícia em vários estados radicalizaram mais ainda as posições na conjuntura.

\section{O Conselho de Segurança Nacional e os protestos estudantis em 1968}

O governo militar emitiu sinal de alerta e, em julho, o Conselho de Segurança Nacional (CSN) fez sua quadragésima primeira reunião da história e debateu a crise em dois momentos (11/07 e 16/07). Em 11/07, o General de Brigada Jayme Portella de Mello (chefe do Gabinete Militar da Presidência da República e Secretário Geral do Conselho de Segurança Nacional) foi o primeiro a fazer um pronunciamento ${ }^{24}$. Afirmou que a situação nacional estava "sendo tumultuada por fatos (...) que representam um desrespeito à autoridade constituída e aos postulados da vida democrática". O general associou as manifestações estudantis de massa aos "atos de terrorismo e sabotagem" ocorridos no Rio de Janeiro e em São Paulo. Estes gestos atentavam contra a ordem pública e o regime. O general enfatizava a insegurança produzida entre a população e a apreensão gerada "no seio das forças Armadas" que liam os fatos como o "início da contrarrevolução". Sentenciava que

\footnotetext{
${ }^{20}$ Visão, 12 abr, 1968, p. 21 Apud VALLE, 1968: o diálogo..., p. 47.

21 "Polícia militar mata estudante", Correio da Manhã, 29 mar. 1968, p. 1 In. VALLE, 1968: o diálogo..., p. 46.

${ }^{22}$ HEGEMEYER, Rafael Rosa. Caminhando e cantando: o imaginário do movimento estudantil brasileiro de 1968. São Paulo: EDUSP, 2016, p. 41-59.

${ }^{23}$ MARTINS FILHO, João Roberto. Os estudantes nas ruas, de Goulart a Collor. In: MARTINS FILHO, 1968 faz 30 anos...., p. 18.

${ }^{24}$ Segundo Muniz de Albuquerque, pronunciamento é o "ato ou efeito de publicamente expressar uma opinião, manifestar-se em defesa de dadas teses, posições políticas, morais, (...). Trata-se do ato de exprimir-se verbalmente; de proferir ou articular um discurso; de ler em voz alta e clara uma peça de oratória; de manifestar o que pensa ou sente; de emitir sua opinião". ALBUQUERQUE JÚNIOR, Durval Muniz. A dimensão retórica da historiografia. In: PINSKI, \& LUCA, O historiador e suas fontes..., p. 225. Albuquerque Júnior oferece várias possibilidades para o trabalho com discursos e pronunciamentos. Este artigo se inspira em algumas delas.
} 
Não parece haver mais dúvidas que as recomendações de Havana $\left[\operatorname{OLAS}^{25} \ldots\right.$...] encontram-se em fase de plena concretização (não só no Brasil como na América Latina), colocando na vanguarda, com vistas à tomada do poder, a classe estudantil, não só universitária como também secundarista. (...) Orientam essas ações elementos especializados com preparo técnico e tático no exterior para o tipo de ação em curso, denominada "Guerrilha Urbana" 26

Chefe do Serviço Nacional de Informações (SNI), o General Emilio Garrastazu Médici identificou a "propagação de ideias marxistas nas escolas secundárias, através de murais, panfletos, manifestos, questionários e jornais escolares (...) [além da] exibição de espetáculos teatrais tipicamente marxistas". Considerou que "essa programação nascida em Moscou e adaptada em Pequim e Havana" estava sendo executada no Brasil. De acordo com sua interpretação, o que se via nas ruas não era mais um ME legítimo "mas um movimento que tem um objetivo nítido, qual seja, o de derrubar o governo revolucionário (...) para posterior implantação da revolução Socialista Brasileira". Para isso, as "esquerdas radicais" com o apoio de "políticos e cassados" estavam utilizando os estudantes como "massa de manobra" para enfraquecer o governo e tomar o poder ${ }^{27}$.

O terceiro pronunciamento na reunião veio igualmente de um membro da caserna. Para o Ministro do Exército, General Aurélio de Lyra Tavares, havia um "processo já bem adiantado de guerra revolucionária" com as recomendações dadas por Havana para tomar o "poder" e "derrubar a Revolução, as suas conquistas, as suas leis e os seus líderes, para que o Brasil volte ao que era antes dele". O General argumentava que "o comunismo e a oposição" estariam unidos para desqualificar as Forças Armadas "sob a capa de um movimento estudantil, que não (...) [era] mais [do que] um processo (...) [para] catequizar e subverter a classe, através de uma minoria atuante e comprometida" que organizava e inseria "na vanguarda do movimento a classe estudantil, tanto os universitários, como, principalmente, os secundaristas" 28 . Além disso, o militar alertava que naquela luta "visando à derrubada das Instituições, o magistério, ante a omissão dos diretores, é infiltrado, trabalhado ou pressionado. Caminha-se, assim, para a solidariedade do professor com o estudante, contra o Governo e, particularmente, contra (...) as Forças Armadas". O medo complementar do apoio dos docentes merece ser extraído deste fragmento. Novamente a ideia da infiltração orienta o diagnóstico, articulada com a crítica à "omissão dos diretores".

Ministro da Aeronáutica, o Brigadeiro Márcio de Souza Mello ressaltou sua "impressão de estar num pesadelo" diante do "perigo" com a sensação que "o organismo não reage ou está impossibilitado de reagir". Sem meias palavras, concluía que a "agitação estudantil, no Brasil, [era] de cunho internacional, conduzida por uma liderança devidamente organizada e comandada".

Os pronunciamentos destes quatro militares ${ }^{29}$ têm uma "relação de coexistência (...) [e suas representações] partilha[m] enunciados, conceitos, objetivos, estratégias" ${ }^{30}$. As representações elaboradas interpretaram a crise estudantil pela chave da guerra revolucionária dirigida por centros externos. O vocabulário desqualifica o direito ao protesto e a relevância das reivindicações que conduziam às manifestações estudantis, associando-as a uma conspiração vinda de fora. A referência à Havana, Pequim e Moscou se converte em argumento para deslegitimar a ação estudantil na cena pública brasileira caracterizando-a como fruto da guerra revolucionária orquestrada pelos comunistas cubanos, chineses e soviéticos.

\footnotetext{
${ }^{25}$ Realizada em Cuba, em outubro de 1967, a Organização Latino-Americana de Solidariedade (OLAS) foi uma reunião da esquerda latino-americana "amplamente divulgada pela imprensa" que reacendeu "nos discursos militares a ameaça iminente do comunismo internacional". CHIRIO, A política nos quartéis..., p. 110.

${ }^{26}$ ATA CSN, 11/07/1968, p. 13.

${ }^{27}$ ATA CSN, 11/07/1968, p. 13.

${ }^{28}$ ATA CSN, 11/07/1978, p. 19.

29 "Os militares" eram marcados por "uma variada gama de cores políticas que se estendia desde aqueles que eram comprometidos com as formalidades da legislação democrática (especialmente os militares oriundos da ESG) até despóticos que as desprezavam vis-à-vis suas utopias autoritárias (extremistas de direita que tinham posições anticomunistas); ou desde os que se batiam por um nacionalismo ufanista baseado nas "grandezas brasileiras" e os que admitiam as insuficiências do país tendo em vista um projeto global de desenvolvimento". FICO, Carlos. Como eles agiam: os subterrâneos da Ditadura Militar: espionagem e polícia política. Rio de Janeiro: Record, 2001, p. 41. A esse respeito, ver MARTINS FILHO, João Roberto. O palácio e a caserna. A dinâmica das crises políticas na ditadura (1964-1969). Tese (Doutorado em Ciência Política). Universidade Estadual de Campinas. Campinas, 1993; CHIRIO, A política nos quartéis...

${ }^{30}$ ALBUQUERQUE JÚNIOR, A dimensão retórica..., p. 235.
} 
De acordo com Chirio, a teoria da Guerra Revolucionária é um "pensamento sobre o inimigo comunista (...) importado da França". Ela surge no Brasil por influência do Exército Francês em 1957. Brasil e Argentina constituiriam as "portas de entrada na América Latina das teorias e técnicas francesas de luta antissubversiva" que seriam difundidas através de algumas Revistas militares e do Estado Maior das Forças Armadas. Documentos, manuais, textos, cursos, palestras, conferências e inserção nos currículos dos cursos de formação - a exemplo da sua instrução na Escola de Aperfeiçoamento de Oficiais - passam a ganhar mais vulto após a ascensão de Goulart à presidência. O conceito se integra ao pensamento da Doutrina de Segurança Nacional - difundida pela Escola Superior de Guerra. Trabalha a noção de guerra total com ênfase na "luta contra o agente comunista infiltrado, veneno ideológico, agitador social e político, artífice da dissolução da unidade nacional, antes de se matamorfosear, armas em punho, em guerrilheiro em busca da conquista do poder" ${ }^{\text {. }}$.

Por essa razão, o General Aurélio de Lyra Tavares (Ministro do Exército) sublinhará os aspectos comuns do que a retórica militar chamará de Movimento Comunista Internacional (MCI). O imaginário anticomunista alimentou recorrentemente que os centros externos eram os verdadeiros financiadores de recursos materiais para diferentes atores da oposição política à ditadura no Brasil. A lógica presente nos pronunciamentos opera com um mix de ingredientes: dissimulação, manipulação, infiltração $e$ corrupção. O objetivo é instaurar a lógica da suspeição demonstrando as intenções subversivas dos atores.

Essa gramática remete ao contexto e ideário da guerra fria. Rodrigo Patto Sá Motta oferece aporte para compreender os aspectos mobilizados pelos membros do Conselho de Segurança. Dos elementos utilizados pelos anticomunistas para destruir a reputação dos adversários, "a ameaça estrangeira" está presente nas falas militares: "a representação do comunismo como ameaça proveniente do exterior guarda relação de proximidade com os temas "doença" e "infiltração", pois tratar-se-ia de um corpo estranho, infiltrado no Brasil por agentes estrangeiros (...) colocando em risco a integridade da nação" 32 .

Na reunião, houve uma única voz dissonante em relação ao argumento da ameaça estrangeira e da internacionalização da subversão. José de Magalhães Pinto (Ministro das Relações Exteriores) enfatizou que a inquietação era mundial. Porém,

sendo essas agitações movimentos locais, os países comunistas não se preocupam muito em vir aqui fazer subversão. Eu não sei dizer se os órgãos de segurança, que estão mais afeitos com o problema, identificaram nesses movimentos estudantis, nesses movimentos de ruas, a presença de estrangeiros. Acredito que não. $\mathrm{O}$ fato é que dentro do próprio país, a inconformidade reinante proporciona uma divulgação muito grande, sobre o modo de agir, de como fazer a Guerra Revolucionária, então, dentro do país aprende-se a fazer isso, não se precisando importar ninguém para o fazer. Acho pois que são medidas de ordem internas que devem ser tomadas para evitar, por exemplo, que a mocidade vá diretamente para esses movimentos ${ }^{33}$.

Nenhum membro do CSN respondeu ao questionamento. Discordando do pressuposto que orientava o diagnóstico de muitos membros do Conselho, o Ministro complementava que a conjuntura demandava cautela e não queria "apoiar, emocionalmente, qualquer medida para depois nos arrependermos de as ter tomado em momento inoportuno. Sou a favor das medidas mais graves [o Estado de sítio ou um novo ato institucional] no momento oportuno e quando forem real".

Emergem dos argumentos associações entre os protestos estudantis e os desejos de derrubada da ordem construindo a imagem dos oposicionistas como contrarrevolucionários. Essa conexão parece ter constituído uma série que moldou o ideário dos militares brasileiros anticomunistas durante a ditadura. Ancorada na análise do discurso militar, Freda Indursky mostrou que "como contrário, o outro pode receber várias representações lexicais (...) tais como adversário da revolução (CB) [Castelo Branco], contrarrevolucionários (CS) [Costa e Silva], inimigo do regime (M) [Médici], agente da traição nacional $(\mathrm{M})$, subversivo e corrupto $(\mathrm{G})$ [Geisel], agitador [CB], inimigo da democracia (CS)" ${ }^{34}$. Aqueles que

\footnotetext{
${ }^{31}$ CHIRIO, A política nos quartéis..., p. 20.

${ }^{32}$ MOTTA, Em guarda contra..., p. 55.

${ }^{33}$ ATA CSN, 16/07/1968, p. 26.

${ }^{34}$ INDURSKY, Freda. As falas dos quartéis e as outras vozes. Campinas, SP: Editora da Unicamp: 2013, p. 144.
} 
discordavam da "revolução de 1964" eram representados como "um outro desprovido de qualquer traço positivo de caráter. Ele é, na melhor das hipóteses, um adversário da revolução e um inimigo do regime".

Ainda inspirado na autora, tais configurações do contrário são generalizadas e enquadradas no mesmo grau de equivalência. Isso explica a operação discursiva que nivelava movimento estudantil, comunismo, oposição, guerrilha, Frente ampla, sabotagens, terrorismo e esquerdas radicais. Tudo isso seria resultado de ação externa. Era antinacional. Nada tinha a ver com o povo brasileiro. Alguns ministros expressaram essa convicção reforçando a lógica acusatória que considera o inimigo como "pouco expressivo, minoritário e perigoso. O tratamento genérico minimiza e desvaloriza o inimigo, ao mesmo tempo em que possibilita traçar-lhe um perfil negativo que justifica o processo de exclusão que sofre: não é brasileiro" 35 . Por isso a sentença: "O grande instrumento dessa Guerra Revolucionária é o Movimento Comunista Internacional (MCI), liderado e financiado pela União Soviética, e que mantém sua unidade, no que respeita ao objetivo final, de enfraquecer o poderio das nações democráticas" ${ }^{36}$.

A ênfase em minimizar a representatividade do movimento - "não tem nada a ver com o povo brasileiro"; "falsos estudantes"; "minorias atuantes" - veio acompanhada da hiperinflação do seu risco à ordem. Essa operação cumpria a função estratégica de mostrar a importância do endurecimento do regime. Além de descortinar esse aspecto, vale demarcar que

(...) o movimento estudantil de 1968 não pode ser confundido com os partidos revolucionários e, particularmente, com as ações armadas então desfechadas, e que receberam, aliás, uma projeção nem um pouco desinteressada. O que não quer dizer que óbvias relações não tenham sido estabelecidas entre estudantes e partidos revolucionários. Mas é preciso evitar as interpretações simplistas que envolvem os movimentos sociais $e$ as ações de "vanguarda" num todo único, negando a autonomia relativa de cada $\mathrm{um}^{37}$.

Ribeiro do Valle sublinhou que "O ME no Brasil não estará sob orientação externa - como afirmará enfaticamente a ditadura -, mas não podemos, contudo, desconsiderar as inspirações provenientes da conjuntura internacional". Prossegue a autora afirmando que esses ventos inspiradores coincidirão com experiências similares do contexto brasileiro $e$ "não significarão apenas a simples importação de ideias". A pesquisadora conclui que "as formas de luta adotadas pelo ME, no entanto, articulam-se com as experiências e proposições revolucionárias internacionais, em especial o guevarismo e o maoismo, táticas de luta que rechaçam o reformismo dos PCs"38.

A única ressalva a ser feita na análise é não esquecer que o ME era atravessado por tensões internas, contradições e algumas delas tinham como foco a relação entre a vanguarda e a maioria dos estudantes. Não há juízo de valor na constatação, mas nem todos os estudantes que participavam das passeatas eram engajados no cotidiano do movimento, no ativismo por dentro das suas estruturas formais, tampouco nas fileiras das diversas correntes políticas que disputavam os rumos gerais do movimento. É necessária cautela ao generalizar para o ME dinâmicas, influências e inspirações que, embora possam eventualmente ter conquistado amplos corações e mentes estudantis, orientavam inicialmente apenas os setores militantes ligados às correntes de esquerda. Martins Filho interpreta com perspicácia essa relação dialética de aproximação/ afastamento entre o conjunto dos estudantes e suas direções políticas, vanguardas militantes:

A análise histórica do movimento estudantil mostra como que um gráfico em que existem duas linhas: a do estudante comum $e$ a do militante, organizado politicamente; em certos momentos existe uma aproximação, quando os setores militantes expressam as grandes aspirações da massa ${ }^{39}$.

\footnotetext{
${ }^{35}$ INDURSKY, As falas dos quartéis..., p. 145.

${ }^{36}$ ATA CSN, 11/07/1968, p. 11.

${ }^{37}$ REIS, Daniel Aarão. 1968, o curto ano de todos os desejos. In: VIEIRA, \& GARCIA (orgs.). Rebeldes e contestadores..., p. 66.

${ }^{38}$ VALLE, 1968: O diálogo..., p. 21.

${ }^{39}$ MARTINS FILHO, Movimento estudanttil..., p. 81.
} 
O contexto inaugurado com o AI-5 evidencia o quanto essa perspectiva analítica é promissora, pois o movimento estudantil de 1968 foi esvaziado pelo novo contexto ditatorial. Se as passeatas após o assassinato de Edson Luís mostraram uma aproximação entre os setores militantes e o estudante comum, após o AI-5 houve um distanciamento entre ambos. Apenas frações de jovens migraram para as organizações de esquerda armada. Por essa razão, o diagnóstico que nivelava movimento estudantil à guerrilha urbana não tinha amparo no contexto em que foi formulado, tampouco no desfecho da crise.

Voltemos para a reunião do Conselho. Ministro da Marinha, o Almirante Augusto Rademaker Grunewald reduziu o problema à leniência na aplicação da lei. Exemplificava que, mesmo proibida, havia passeata; estudantes queimavam "bandeira de um país amigo" e o responsável não era preso. Segundo ele, existiam meios para as sanções, sem necessidade de legislação de exceção. Apontava ainda que "estudantes têm é que estudar. As universidades precisam dar trabalho aos alunos, eles estão, como que, numas férias prolongadas. Todos temos filhos e sabemos. (...) O estudante que não trabalha tem tempo para a subversão" ${ }^{40}$. O almirante cerrava fileiras com o argumento que "estudante é para estudar" - bordão anticomunista e conservador que intitulou campanhas do Instituto de Pesquisas e Estudos Sociais (IPES) antes do golpe ${ }^{41}$.

Quase todos os ministros esboçaram críticas à imprensa. O General Aurélio de Lyra Tavares (Ministro do Exército) sublinhou que "os jornais continuam a dar cobertura ao movimento, anunciando as reuniões, com fotografias e manchetes, e pondo em destaque (...) a União Nacional dos Estudantes, embora se trata de entidade ilegal, de funcionamento clandestino, cuja ação subversiva serviu de base ao Governo deposto pela Revolução"42. Luis Gama e Silva (Ministro da Justiça) abordou a questão de modo contundente: "a contrarrevolução está na imprensa". Antônio Delfim Netto (Ministro da Fazenda) enfatizou os prejuízos materiais em razão do funcionamento e ação daqueles "que dispõem do monopólio da informação falsificada". O Almirante de Esquadra José Moreira Maia (Chefe do Estado Maior da Armada) criticou a manipulação da imprensa ao diálogo promovido pelo Governo com os estudantes ${ }^{43}$. Para ele, a ação da imprensa teria sido a "de obscurecer a grandeza da atitude incomum de Vossa Excelência" ${ }^{44}$.

A imprensa foi acusada de distorcer os fatos, inventar rumores, apresentar dados falsos, estimular perspectivas alarmistas, ser financiada para dar cobertura positiva à subversão "e aos projetos de sustentação da contrarrevolução" ${ }^{45}$. Ribeiro do Valle salientou que "por causa do alarmante crescimento do "movimento subversivo" (...) com o acirrar dos conflitos, o governo ameaça a imprensa por contribuir para o alastramento da "agitação", ensaiando os primeiros passos da censura" 46 .

Muitos dos presentes à reunião não se abstiveram em afirmar que o objetivo do protesto estudantil e dos seus aliados era retroceder ao "tempo de antes". O General Aurélio de Lyra Tavares (Ministro do Exército) sublinhou: "derrubar a Revolução, as suas conquistas, as suas leis e os seus líderes, para que o Brasil volte ao que era antes dele, sob o comando dos que, frustrados nos seus desígnios de comunizá-lo, foram cassados e banidos do poder" ${ }^{\text {47. }}$. O Deputado Tarso de Moraes Dutra (Ministro da Educação e Cultura) comentou que era a "contrarrevolução em marcha, o revanchismo nas ruas, a preparação das condições que tornarão possível, pela relação direta e premeditada de muitos $e$ a ingênua faculdade de não poucos, o retorno à situação anterior a março de hum mil novecentos $e$

\footnotetext{
${ }^{40}$ ATA CSN, 11/07/1968, p. 18.

${ }^{41}$ Esse argumento anticomunista e conservador parece ser transnacional. A Reforma curricular imposta pela ditadura chilena expandiu a carga horária dos estudantes universitários daquele país sob esse mesmo pressuposto: quanto mais tempo ocupado com estudo, menos a mente estudantil divagaria para a subversão...A respeito, ver BAEZA CORREA, Jorge. Referencias para un análisis del discurso del gobierno militar chileno sobre el movimiento estudiantil universitario: 1973-1980. Lit. lingüíst. [online]. 2004, n.15 [citado 2018-01-24], pp. 253-286. Disponível em: $<$ https://scielo.conicyt.cl/scielo.php?script=sci arttext\&pid=S0716-58112004001500015\&lng =es\&nrm =iso $>$.

${ }^{42}$ ATA CSN, 11/07/1968, p. 18

${ }^{43}$ Percebendo a amplitude da indignação contra o governo, Costa e Silva "se dispôs a receber a comissão representativa dos organizadores da passeata. Nada resultou do diálogo, mas esta foi a única vez que um general-presidente concedeu audiência a uma comissão popular". GORENDER, Jacob. Combate nas Trevas. 2a ed. São Paulo: Ática, 1987, p. 148.

${ }^{44}$ ATA CSN, 11/07/1968, p. 20.

${ }^{45}$ ATA CSN, 11/07/1968, p. 11.

${ }^{46}$ VALLE, 1968: O diálogo..., p. 29.

${ }^{47}$ ATA CSN, 11/07/1968 p. 16.
} 
sessenta e quatro" ${ }^{48}$. Os exemplos mostram os usos políticos do passado e a lembrança recorrente do fantasma do Governo Goulart para reforçar coesão nos membros do CSN, leituras comuns do presente e projetos para que o futuro não repetisse o passado.

Além da preocupação com a disputa da "opinião pública" para enfraquecer o risco de retrocesso, a reunião trouxe à baila observações sobre eventuais prejuízos materiais gerados pela "agitação política". O General Aurélio de Lyra Tavares (Ministro do Exército) mencionou "a apreensão e os prejuízos revelados, em apelos ao Ministério do Exército, pelo Comércio, órgãos da Indústria, classes conservadoras e numerosas famílias, ansiosas pelo restabelecimento da segurança e da tranquilidade que lhes são devidas"49. Antônio Delfim Netto (Ministro da Fazenda) concordou com o sentido e atribuiu a Lenin a autoria da frase: "o caminho mais fácil para destruir a ordem constituída num País é destruir a sua moeda". Prosseguiu com o seguinte comentário:

(...) na semana passada fomos obrigados a emitir cento e cinquenta milhões de cruzeiros novos, porque as agitações levam o povo aos bancos retirando suas economias, porque espera que na sexta-feira vai acontecer isso, na quinta-feira vaí acontecer aquilo. Fora isso há e houve, o presidente da república tem conhecimento completo de uma ação contra a nossa moeda, comandada de fora, por instituições financeiras internacionais e levantada em cinco ou seis relatórios. (...) o prejuízo de arrecadação na semana ou no mês em que se verificou as maiores agitações (...) foi no mês de junho. Na Guanabara, onde uma estimativa rigorosa previu uma arrecadação de cento e sessenta $e$ oito milhões de cruzeiros novos e arrecadamos cento e vinte $e$ cinco, isto é quarenta e três milhões de cruzeiros novos não entraram. Importância que significa (...) quase quarenta quilômetros de estrada, (...) todo o programa de irrigação do Ministro do Interior, (...) talvez dois terços do programa de telecomunicações do Ministro das Comunicações. Isso dá uma ideia física da destruição a que se pode permitir àqueles que dispõem do monopólio da informação falsificada.

Noso foco não é discutir a interpretação nem a pertinência dos dados. O que vale ser imaginado é o eventual impacto dessa informação entre os membros do staff. Uma espécie de "realismo econômico" era mobilizado sobre as repercussões negativas do avanço da "contrarrevolução" em diversos níveis. A conspiração internacional não era apenas no plano político-ideológico. Delfim Netto creditava o papel de sabotagem a grupos econômicos internacionais - ratificando observações anteriores que ampliavam o bloco da subversão conferindo lugar especial para grandes grupos econômicos internacionais $e$ empresários do ramo especulativo.

Outros receios afloraram na reunião. Para o General Aurélio de Lyra Tavares (Ministro do Exército), "o ambiente de agitação e a catequese ideológica no meio estudantil" preocupavam "comandantes de unidades" que identificaram "casos (...) de infiltração no quartel". A subversão teria criado "o conceito do soldado-estudante para contaminar o espírito do recruta, repetindo-se os casos de jovens que se apresentam para servir (...) já devidamente instruídos e orientados para missões de informação". O Comandante da Academia Militar teria identificado "cadetes componentes de um grupo de catequeses e propaganda subversiva". Para o Ministro, aqueles fatos revelavam "o grau de contaminação do ambiente estudantil" com a finalidade de servir à subversão ${ }^{50}$.

Ao tecer o diagnóstico da área, o Coronel Mario Andreazza (Ministro dos Transportes) sublinhava que entre os "portuários, ferroviários e marítimos, a situação é de calma, não obstante as sucessivas tentativas para agitá-las". O ministro salientava ser "grande o número de pessoas estranhas a essa área que procura penetrar, para agitar e associar os portuários, ferroviários e marítimos em movimentos estudantis" 51 .

O Secretário Geral Jayme Portella de Mello relatou que "a massa sindical nacional (...) está sendo disputada pelos "grupos esquerdistas"; que "a alta inevitável do custo de vida, o problema assistencial $e$ as questões salariais" ameaçavam a contenção do operariado e que a previsão era de "agravamento a partir de agosto com a realização da $3^{\text {a }}$ Conferência Nacional dos Dirigentes Sindicais, que,

\footnotetext{
${ }^{48}$ ATA CSN, 16/07/1964, p. 04

${ }^{49}$ ATA CSN, 11/07/1968, p. 18.

${ }^{50}$ ATA CSN, 11/07/1968, p. 18.

${ }^{51}$ ATA CSN, 16/07/1968, p. 6.
} 
provavelmente, buscará a radicalizar a luta contra o Regime". Concluía que era "grande a probabilidade de que a massa sindical venha a participar do processo revolucionário em marcha" 52 . Para o Senador Jarbas Passarinho (Ministro do Trabalho e Previdência Social), a "área estudantil tem reflexos imediatos na área do trabalho", pois muitos bancários eram estudantes e era "evidente que volta e meia vão os estudantes tentar levantar esses trabalhadores, junto aos seus sindicatos". O Presidente Costa e Silva considerou que as notícias eram promissoras, mas que exigiam "uma pessoa especial para essa área, porque seria então uma desgraça maior se aos estudantes (...) se juntassem os operários" 53 .

O Marechal Marcio de Souza e Mello (Ministro da Aeronáutica) demonstrou medo com "a participação das mães de família" nas últimas passeatas. Alertava que "a família é célula da sociedade e se ela for rompida, como se rompe o átomo, desencadear-se-á então, a explosão em série e a coisa, ficará incontida. Se é difícil reprimir a juventude numa demonstração dessas, mais difícil ainda é nos opormos às mães de família"54.

Algo comum nos diversos pronunciamentos é a vigência de uma gramática anticomunista. "Subversão", "catequese", "catequizar", "infiltrados", "infiltração", "falsos estudantes", "massa de manobra", "contaminação"... O jargão reitera a suspeição em torno do "inimigo interno", suas supostas conexões internacionais e a reprodução da subversão como quase uma doença a se alastrar em todas as esferas da vida social: a família, os quartéis, as escolas, as universidades, a imprensa, a igreja, as indústrias, os portos; a economia, a política, a arte, a educação, a religião; professores, militares, trabalhadores, padres, jornalistas, intelectuais, políticos, empresários. Sujeitos, territórios, dimensões da vida. Nada escapava aos desígnios da subversão. Tudo estaria potencialmente contaminado pela "conspiração maléfica" por esse agente do "complô [que] desabrocha na fetidez obscura; confundido com os animais imundos, rasteja e se insinua; viscoso ou tentacular, espalha o veneno e a infecção..." 55 .

Caracterizar o comunismo como enfermidade e os comunistas como seres doentes e/ou nocivos implicou associar sua ação política a "doenças e temas correlatos como peste, praga, bacilo, veneno, vírus, câncer etc. (...) A ação dos comunistas era apresentada como similar ao trabalho dos agentes infecciosos nos organismos vivos" 56 . Como decorrência, emergiram noções de empréstimo do jargão médico aplicadas ao mundo social. Essa gramática possuía no seu repertório palavras e expressões como desintoxicar, dissolução moral, contaminação, infecção, vírus extremista, infiltração etc.

A noção de "guerra total" orientava o diagnóstico do Conselho de Segurança Nacional. Obviamente, nem todas as palavras estavam soltas ao ar. Sem perder de vista o caráter sigiloso da reunião, os pronunciamentos contribuíam para delimitar campos políticos, disputar hegemonia, exercer poder, desenhar cenários, causar efeitos, produzir (ou evitar) fatos políticos. Mais especificamente, visavam criar estados de ânimo a respeito dos rumos do regime, fortalecer sentimentos de identidade, especialmente o anticomunismo e o consenso na crítica ao "tempo de antes da revolução de 1964". As atas permitem inferir sobre o protagonismo dos militares no diagnóstico e soluções da questão. A própria reunião do CSN - e o teor das falas dos seus membros - é um acontecimento relevante para o aumento do poder dos militares no governo. Ao abrir a segunda sessão da reunião ocorrida em 16/07/1968, Costa e Silva demarcou sem subterfúgios:

É evidente que as conclusões mais importantes já foram feitas, de vez que já falaram o Serviço Nacional de Informações, o Estado Maior das Forças Armadas, o Ministro da Justiça, o Ministro das Relações Exteriores, bem como foi lido o Relatório do Secretário geral do Conselho de Segurança Nacional. A Aeronáutica também já falou, falaram as Forças Armadas de modo geral. Pediria agora, que houvesse uma exposição rápida de cada Ministro. Pediria que cada Ministro expedisse um parecer sintético sobre a situação, que por sinal é muito simples. Nós estamos aqui justamente para decidir se o momento impõe medida de exceção ou não. Eu quero é que cada

\footnotetext{
${ }^{52}$ ATA CSN, 11/07/1968, p. 4.

${ }^{53}$ ATA CSN, 11/07/1968, p. 33.

${ }^{54}$ ATA CSN, 11/07/1968, p. 19

${ }^{55}$ GIRARDET, Raoul. Mitos e mitologias políticas. São Paulo: Companhia das Letras, 1987, p. 17.

${ }^{56}$ MOTTA, Em guarda contra..., p. 53.
} 
Ministro dê o seu parecer rápido, opinando pelo sim ou pelo não ${ }^{57}$.

Este comentário sugere a "militarização da questão estudantil", na medida em que Costa e Silva sinalizou que as conclusões mais importantes já tinham sido apontadas a partir dos pronunciamentos militares. Chama a atenção que o Ministro da Educação e Cultura - um civil - ainda não havia se posicionado! No tabuleiro da política, este trecho reitera a ampliação do poder dos militares no diagnóstico e na condução das orientações gerais sobre como o governo deveria lidar com a oposição, embora a reunião não tenha aprovado o estado de sítio nem novo ato institucional.

Um último tópico merece ser abordado. A dimensão moral do problema estudantil não escapou à percepção dos membros do Conselho. O General Jayme Portella de Mello identificou a "ausência de orientação moral e cívica da juventude" enquanto um dos "fatores que favorecem a ação subversiva". Alertou para os apelos feitos ao Ministério do Exército de "numerosas famílias, ansiosas pelo restabelecimento da segurança e da tranquilidade que lhes são devidas". O Deputado Tarso de Moraes Dutra (Ministro da Educação e Cultura) reafirmou que, entre "os objetivos da revolução", estariam "impor a moralidade dos costumes" 58 .

Esses fragmentos apresentam continuidade com a retórica do golpe de 1964 e sua intenção de "reconstrução moral da nação". Habilmente interpretada pelos militares como o chamado da sociedade brasileira para a intervenção, a principal mobilização massiva na cena pública de oposição ao governo Goulart - a Marcha com Deus, pela Família e pela Liberdade - colocou em pauta uma ideia de família e noções de moralidade. Em um clássico sobre a ideologia de segurança nacional, Comblin traçou um breve comentário a respeito da relação entre política e moral durantes as ditaduras latino-americanas. Segundo o autor:

Quanto mais ditatorial e violento for um Estado, mais ele tratará a nação como inimiga, e quanto mais proclamar pretensões de moralidade, mais edificante, moralista e espiritual será sua linguagem - a tal ponto que qualquer aula de moral vinda de um Chefe de Estado desperta imediatamente uma sensação de medo. (...) A se acreditar neles, suas ditaduras não têm outra meta senão restaurar a moralidade da nação ${ }^{59}$.

Além da retórica moral em geral, houve pronunciamentos abordando como noções subversivas de moralidade impactavam os jovens. O Deputado Tarso de Moraes Dutra (Ministro da Educação e Cultura) atribuiu ao italiano Viscont - um diretor de cinema que se assumia homossexual - a ideia de que os jovens "são as crianças escolhidas (...) [e] os centros internacionais da subversão estão procurando aproveitar e explorar, em seus desígnios de destruição do poder dominante, as condições especiais de uma geração formada de filhos de pais mais tolerantes". O Presidente Marechal Costa e Silva enfatizou:

As fotografias demonstram meninas e mocinhas envolvidas nas agitações (...). Houve uma concentração de meninos (...) que lá passaram uma noite (...) dando demonstração de falta de educação no lar e de controle por parte daqueles de mais responsabilidade, dos responsáveis até pela honra de suas filhas, porquanto passaram uma noite em comum, promiscuamente, dentro de um ambiente definido, pelo (...) Diretor do Senado, (...): "transformaram isso aqui, num lupanar" (ATA CSN, 16/07/1968, p. 29).

As palavras acima estão impregnadas de conteúdo político e moral. A leitura da contestação estudantil a serviço da subversão internacional veio acompanhada da preocupação com as "meninas e mocinhas" se socializando, dormindo com meninos num mesmo espaço e sem controle por parte dos pais, responsáveis pela "honra de suas filhas". A dimensão moral está ancorada em noções naturalizadas de família, de jovem, de homem, de mulher e de relações de gênero.

Os autores evidenciam um desconforto com comportamentos que pareciam subverter aquelas noções, lugares e papeis sociais. Eram sujeitos que ocupavam postos-chave no governo e no aparelho

\footnotetext{
${ }^{57}$ ATA CSN, 16/07/1968, p. 2.

${ }^{58}$ ATA CSN, 16/07/1968, p. 6.

${ }^{59}$ COMBLIN, Padre Joseph. A Ideologia de Segurança Nacional. Rio de Janeiro: Civilização Brasileira, 1977, p. $222-223$.
} 
de estado. Possivelmente, estavam em pânico pelas experiências contestatórias protagonizadas por jovens em âmbito internacional naquele primeiro semestre, bem como se nutriam do imaginário anticomunista nos discursos sobre a juventude. Vistos pelos religiosos como "adversários irreconciliáveis da moralidade cristã tradicional", os comunistas "desejariam destruir o pilar básico do edifício cristão, a família, que constituía a base da instituição religiosa e da própria sociedade" ${ }^{60}$. No caso da juventude, agiriam para corromper os jovens, degradá-los moralmente, implodir suas famílias, solapar noções de decência, dignidade e comedimento, estimular sua perversão sexual, instigar a libidinagem, manipular e destruir jovens inocentes...

\section{Considerações finais}

O Conselho tratou os protestos estudantis do $1^{\circ}$ semestre de 1968 majoritariamente sob a chave da guerra revolucionária e da subversão internacional. Em meio ao processo de ampliação da militarização e do fortalecimento do próprio Conselho na conjuntura, o tom predominante foi desqualificar as reivindicações estudantis e acionar representações anticomunistas para combater o que parecia ser a "contrarrevolução". Marcados por generalizações pouco fundamentadas em evidências concretas, os pronunciamentos tinham fundo ideológico e certamente contribuíram para criar um estado de ânimo traduzido entre uma aparente negociação e o efetivo endurecimento do Governo na relação com as lutas estudantis.

A $2^{a}$ seção da reunião do Conselho (16/07) foi encerrada sem a aprovação do estado de sítio, tampouco do novo ato institucional. Mas os cenários foram desenhados. Um Ministro profetizou que, "se a adoção de outras medidas, (...) não tiverem o efeito de corrigir a crise institucional brasileira, novos caminhos (...) devem ser criados para que não pereçam os objetivos da revolução".

E a luta política continuou dinâmica. Passado o mês de julho, o Conselho voltaria a se reunir em dezembro. Até lá, a temperatura subiu e a conjuntura teve no enredo sucessivas crises na caserna; novos protestos estudantis de massa e conflitos com a polícia nas ruas, palcos e praças; críticas vorazes ao regime pela imprensa; apresentação da proposta de Reforma Universitária do Governo; ações violentas pelas esquerdas; invasão da Universidade de Brasília; desmantelamento do $30^{\circ}$. Congresso da UNE com a prisão de todos os estudantes; impasses no Congresso Nacional. O desenlace foi marcado pela edição do AI-5, aprovado pelo $\mathrm{CSN}^{61}$. Marco da entrada da ditadura na fase do Terrorismo de Estado, o Ato 5 radicalizou e expandiu o ciclo de intolerância à oposição. A universidade não foi blindada, tampouco intelectuais, artistas, jornalistas, professores. O Decreto 477 (fevereiro, 1969) ampliou uma legislação repressiva que fez o movimento estudantil massivo desaparecer da cena pública.

Desarticulado o movimento estudantil amplo na cena pública, frações de jovens migraram para as organizações de esquerda armada. A partir da análise dos processos judiciais instalados pelo regime para apurar a "subversão", Marcelo Ridenti ${ }^{62}$ mostrou que "73,5\% dos acusados de envolvimento com os grupos armados tinham entre 19 e 30 anos". De outro lado, a revolução dos costumes se expandia desaguando na percepção de uma subversão da moral internacionalmente conspirada pelos comunistas. Ao lado das representações anticomunistas clássicas construídas sobre os protestos estudantis de 1968, novas ansiedades, medos e perigos relacionados aos jovens pautariam a agenda anticomunista e conservadora.

\footnotetext{
${ }^{60}$ MOTTA, Em Guarda contra..., p. 62.

${ }^{61}$ De acordo com Carlos Fico, o vice-presidente Pedro Aleixo "foi o único membro do Conselho de Segurança Nacional a cogitar de uma saída constitucional na reunião que aprovou o AI-5". FICO, Como eles agiam..., p. 63.

${ }^{62}$ RIDENTI, Marcelo. O fantasma da revolução brasileira. São Paulo: Editora da Universidade Estadual Paulista, 1993, p. 120.
} 


\section{RESUMO}

O artigo examina como o Conselho de Segurança Nacional avaliou o protesto estudantil no Brasil em 1968. Investiga os pronunciamentos dos seus membros em duas seções convocadas pelo Marechal Costa e Silva (Presidente da República) para discutir a crise política. Discorre sobre as principais interpretações dos Ministros e conselheiros sobre as lutas estudantis à luz das tensões $e$ incertezas presentes no contexto. A percepção de como o Conselho avaliou o movimento estudantil ajuda a compreender aspectos da conjuntura de 1968 e das representações anticomunistas elaboradas sobre a juventude crítica ao regime no tempo da ditadura.

Palavras-chave: Movimento estudantil; Anticomunismo; Conselho de Segurança Nacional

Artigo recebido em 01 ago. 2018.

Aprovado em 17 set. 2018.
ABSTRACT

The article examines how the National Security Council evaluated the student protest in Brazil in 1968. It investigates the pronouncements of its members in two sections convened by Costa e Silva (President of the Republic) to discuss the political crisis. It discusses the main interpretations of Ministers and Counselors on student struggles in the light of the tensions and uncertainties present in the context. The perception of how the Council evaluated the student movement helps to understand aspects of the conjuncture of 1968 and the antiCommunist representations elaborated on youth critical of the regime during the dictatorship.

Keywords: Student Movement; Anticommun ism; National Security Council 
SÆCUlum - Revista de HistóRIa [39]; João Pessoa, jul./dez. 2018. 